\title{
GAMBARAN PERILAKU HIDUP BERSIH DAN SEHAT DI PONDOK PESANTREN NURUL HUDA SURABAYA
}

\author{
Muhamad Khafid \\ (Universitas Nahdlatul Ulama Surabaya, Email:khafid@unusa.ac.id) \\ Nur Ainiyah \\ (Universitas Nahdlatul Ulama Surabaya, Email:ainiyahannuri@unusa.ac.id) \\ Siti Maimunah \\ (Universitas Nahdlatul Ulama Surabaya, Email:maimunah@unusa.ac.id)
}

\begin{abstract}
ABSTRAK
Pondok Pesantren adalah lembaga pendidikan agama yang berkembang di masyarakat, serta mempunyai peranan penting dalam mengembangkan sumber daya manusia. Pengembangan sumber daya manusia tidak lepas dari peran pemimpin dan pengelola serta santri di pondok pesantren. Seluruh penghuni pondok pesantren diharapkan kompeten dalam aspek pembangunan moral, spiritual dengan intelektual yang bernuansa agamis, juga menjadi motor penggerak, motivator dan inovator dalam pembangunan kesehatan, termasuk teladan dalam berperilaku hidup bersih dan sehat. Pondok Pesantren Nurul Huda Sencaki Surabaya merupakan salah satu pondok pesantren yang belum optimal dalam melaksanakan PHBS sehingga muncul beberapa masalah kesehatan. Penelitian ini adalah penelitian kualitatif lapangan yang bermaksud untuk memahami fenomena yang dialami oleh subyek penelitian. Pendekatan yang digunakan adalah pendekatan fenomenologi. Data dikumpulkan dengan metode wawancara dan kuesioner. Analisis yang digunakan adalah analisis deskriptif. Hasil penelitian menunjukan bahwa lebih dari dari separoh santri belum melaksanakan Program Perilaku Hidup Bersih dan Sehat (PHBS) yaitu 54,7\%. Tingkat pengetahuan tentang PHBS masih rendah yaitu 59.4\%. Santri mempunyai sikap terhadap PHBS sebesar 75\%, dan kurangnya peran guru terhadap PHBS sebesar $56.3 \%$.
\end{abstract}

Kata Kunci: Perilaku, PHBS, pondok pesantren

\begin{abstract}
Islamic boarding school is a religious education institution that develops in the community, and has an important role in developing human resources. Human resource development is inseparable from the role of leaders and managers as well as students in Islamic boarding schools. All boarding school dwellers are expected to be competent in the aspects of moral development, spiritual development with intellectual nuances of religion, as well as being a driving force, motivator and innovator in health development, including role models in clean and healthy living behavior. Nurul Huda Islamic Boarding School Surabaya Sencaki is one of the boarding schools that have not been optimal in implementing PHBS so that several health problems arise. This research was a qualitative field research that intends to understand the phenomena experienced by research subjects. The approach used was the phenomenological approach. Data were
\end{abstract}


collected by interview and questionnaire methods. The analysis used descriptive analysis. The results showed that more than half of the students had not yet implemented the Clean and Healthy Behavior Program (PHBS), namely 54.7\%. The level of knowledge about PHBS is still low at 59.4\%. Santri has an attitude towards PHBS by 75\%, and the lack of the teacher's role towards PHBS by $56.3 \%$.

Keywords: Behavior, PHBS, Islamic boarding school

PENDAHULUAN

Pembangunan kesehatan merupakan upaya yang dilaksanakan dengan tujuan untuk meningkatkan kesadaran, kemauan, dan kemampuan hidup sehat bagi setiap orang agar termasuk seluruh santri pondok pesantren agar terwujud derajat kesehatan yang setinggitingginya.derajat kesehatan yang baik adalah sebagai investasi bagi pembangunan sumber daya manusia yang produktif secara sosial dan ekonomis. Perilaku hidup bersih dan sehat (PHBS)merupakan salah satu cara mencapai derajat kesehatan yang baik. Keberhasilan pembangunan kesehatan juga ditentukan oleh kesinambungan antar upaya program dan sektor, serta kesinambungan dengan upaya-upaya yang telah dilaksanakan oleh periode sebelumnya (Kementrian Kesehatan Republik Indonesia, 2015). Oleh karena itu peningkatan PHBS sangat diperlukan sekali dalam lingkungan pondok pesantren.

PHBS pondok pesantren memiliki beberapa indikator antara lain kebersihan individu, tempat wudhu, penggunaan air berswih, jamban sehat, kebersihan asrama, ruang belajar serta kepadatan penghuni asrama. Untuk mencapai indikator tersebut, peran dan fungsi poskestren (pos kesehatan pesantren) juga sangat dibutuhkan.
Poskestren di Pondok Pesantren Nurul Huda Sencaki Surabaya belum optimal menerapkan program poskestren untuk meningkatkan derajat kesehatan warga pesantren termasuk penerapan pola hidup bersih dan sehat. Selama ini pembinaan kesehatan baik secara Promotif, Preventif , Kuratif dan Rehabilitatif hanya dilakukan oleh pihak Puskesmas setempat. Seluruh santri, tenaga pendidik, Pembina maupun masyarakat di lingkungan pondok pesantren harus ditingkatkan penerapan PHBS nya (Hasanah N, 2016). Hal tersebut belum terbia optimal di pondok pesantren Nurul Huda sehingga pemberdayaan kesehatan dilingkungan Pondok Pesantren belum terlaksana secara menyeluruh, dampaknya adalah masih terdapat masalah kesehatan yang disebabkan oleh kurangnya perilaku hidup bersih dan sehat.

Beradasarkan wawancara dengan beberapa santri di pondok pesantren Nurul Huda Sencaki Surabaya, masalah kesehatan yang sering diderita oleh santri, yaitu: scabies, gangguan pencernaan (diare dan gastritis), sesak nafas dan batuk pilek. Menurut mereka, informasi kesehatan selama ini masih minimal, karena santri dipadatkan dengan jadwal sekolah dan jadwal keagamaan di pondok pesantren. Penelitian yang dilakukan oleh Nasution (2011), menyatakan bahwa ada pengaruh pembinaan lingkungan 
sekolah sehat dan ketenagaan dengan pelaksanaan program Usaha Kesehatan Sekolah.

Berdasarkan uraian diatas, peneliti tertarik untuk melakukan penelitian dengan judul mengetahui "Gambaran Perilaku Hidup Bersih dan Sehat (PHBS) di Pondok Pesantren Nurul Huda Sencaki Surabaya".

\section{METODE PENELITIAN}

oleh penelitian yang dilakukan kualitatif lapangan. Penelitian kualitatif adalah penelitian yang bertujuan untuk memahami fenomena yang dialami oleh subyek penelitian. Pendekatan yang digunakan adalah pendekatan fenomenologi dengan maksud mencari dan menemukan makna dari hal-hal yang mendasar dari pengalaman- pengalaman hidup subyek penelitian terkait perilaku hidup bersih dan sehat di pondok pesantren. Peneliti mempelajari fenomena yang terjadi di pondok pesantren kemudian hasil data dianalisis menggunakan uraian deskriptif berupa kata-kata tertulis.

Penelitian dilaksanakan di pondok pesantren Nurul Huda Sencaki Surabaya pada bulan Agustus 2019 dengan jumlah responden sebanyak 106 santri dengan pendidikan SLTP dan SLTA. Analisis data yang digunakan peneliti adalah analisis data deskriptif.

\section{HASIL}

Pelaksanaan Perilaku Hidup Bersih dan Sehat (PHBS) di pondok pesantren Nurul Huda Sencaki masih rendah. Rendahnya PHBS dapat mengakibatkan masalah kesehatan yang akan mempengaruhi kualitas kesehatan seluruh penghuni lingkungan pondok, angka penyakit juga akan meningkat terutama pada anak didik. Memperkenalkan dunia kesehatan pada seluruh santri di pondok pesantren, sebenarnya cukup mudah salah satunya dengan membuat poskestren dan membudayakan praktek pelaksanaan PHBS dalam kehidupan sehari-hari.

Hasil penelitian menunjukan bahwa lebih dari dari separoh santri belum melaksanakan Program Perilaku Hidup Bersih dan Sehat (PHBS) yaitu 54,7\%. Tingkat pengetahuan tentang PHBS masih rendah yaitu 59.4\%. Santri mempunyai sikap terhadap PHBS sebesar $75 \%$, dan kurangnya peran guru terhadap PHBS sebesar 56.3\%.

\section{PEMBAHASAN}

Tingkat pengetahuan santri mengenai PHBS yang masih rendah dikarenakan kurangnya peran tenaga pendidik dan tenaga kesehatan dalam memberikan informasi dan promosi kesehatan mengenai PHBS. Promosi kesehatan dapat diberikan melalui penyuluhan dan demonstrasi langsung mengenai PHBS, serta kurangnya pelatihan terhadap tenaga pendidik. Pengetahuan sangat perlu diberikan kepada santri karena akan menunjang terbentuknya perilaku hidup bersih dan sehat, perilaku yang membudaya dalam setiap aktifitas. Pemikiran yang positif akan terbentuk jika santri dan seluruh pengasuh serta tenaga pendidik sudah mengetahui dan mempraktikkan Perilaku Hidup Bersih dan Sehat (PHBS) di pondok pesantren. 
Terbentuknya sikap santri dipengaruhi oleh pengetahuan dan pengalaman yang diperolehnya baik dari pondok maupun dari luar. Oleh sebab itu peran tenaga pendidik dan pengelola serta tenaga kesehatan sangat mempengaruhi terutama dalam hal penyampaian informasi tentang pelaksanaan Program Perilaku Hidup Bersih dan Sehat (PHBS) pondok pesantren.

Santri cenderung melakukan metode pembelajaran imitasi yaitu meniru perilaku orang lain terutama orang tua, guru?ustadz serta teman dalam lingkungannya, termasuk meniru perilaku hidup bersih dan sehat. Santri bisa dapat lebih percaya terhadap kiyai, ustadz/guru dibandingkan pada orang tua mereka sendiri. Oleh karena itu tenaga pendidik dan pengelola pondok pesantren harus bisa menunjukan sikap dan keteladanan dan kewibawaan yang baik di hadapan santrinya. Keteladanan dan kewibawaan rnerupakan syarat mutlak mendidik dan membimbing santri yang akan bermanfaat untuk meningkatkan peran pengelola dan tenaga pendidik terhadap pelaksanaan Program Perilaku Hidup Bersih dan Sehat (PHBS) di pondok. Sehingga promosi kesehatan terkait PHBS juga perlu diberikan kepada tenaga pendidik dan pengelola pondok pesantren.

\section{SIMPULAN}

Berdasarkan hasil penelitian dapat disimpulkan sebagai berikut :

1. Gambaran PHBS santri di pondok pesantren Nurul Huda Sencaki Surabaya belum terlaksana dengan optimal.

2. Perilaku Hidup Bersih dan Sehat (PHBS) yaitu 54,7\%. Tingkat pengetahuan tentang PHBS masih rendah yaitu 59.4\%. Santri mempunyai sikap terhadap PHBS sebesar $75 \%$, dan kurangnya peran guru terhadap PHBS sebesar $56.3 \%$

\section{DAFTAR PUSTAKA}

Adliyani, Z. O. N. (2015). Pengaruh perilaku individu terhadap hidup sehat. Jurnal Majority, 4(7), 109-114.

Afiyah, A. (2017). Sistem Pendidikan Tauhid di Pondok Pesantren Darul Muttaqin, Desa Bukateja, Kecamatan Balapulang, Kabupaten Tegal Tahun Ajaran 2016/2017 (Doctoral dissertation, Fakultas Tarbiyah dan Ilmu Keguruan).

Dinas Kesehatan Provinsi Jawa Timur. (2017). Profil Kesehatan Provinsi Jatim Tahun 2017.

Efendi, F., \& Makhfudli, M. (2010). Keperawatan kesehatan komunitas. Jakarta; EGC

Heimberg, R. G., \& Becker, R. E. (2002). Cognitivebehavioral group therapy for social phobia: Basic mechanisms and clinical strategies. Guilford Press.

Ikhwanudin, A. (2013). Perilaku Kesehatan Santri:(Studi Deskriptif Perilaku Pemeliharaan Kesehatan, Pencarian dan Penggunaan Sistem Kesehatan Dan Perilaku Kesehatan Lingkungan Di Pondok Pesantren Assalafi Al Fithrah, Surabaya). Jurnal Sosial dan Politik, 2(2), 3. 
Jamaluddin, M. (2012).

Metamorfosis Pesantren Di Era

Globalisasi. KARSA: Journal of

Social and Islamic Culture, 20(1), 127-139.

Kementrian Kesehatan Republik Indonesia. (2015). Profil Kesehatan Indonesia 2014. Jakarta: Kementrian Kesehatan $R I$.

Lina, H. P. (2017). Perilaku Hidup Bersih dan Sehat (PHBS) Siswa di SDN 42 Korong Gadang Kecamatan Kuranji Padang. Jurnal Promkes, 4(1), 92-103.

Maulana, H, D. (2009). Promosi kesehatan. Jakarta; EGC

Notoatmodjo, S. (2007). Kesehatan masyarakat. Jakarta: Rineka Cipta.

Rorimpandey, H. M., Rattu, A. J. M., \& Tumuraang, M. N. (2015). Faktor-Faktor Yang Berhubungan Dengan Perilaku Hidup Bersih Dan Sehat (PHBS) Pada Siswa Di SMP Negeri 2 Tompaso. Tumou Tou, 1(2). 